\title{
Trichodynia: An Update on Definition, Etiopathogenesis, Diagnosis, and Treatment
}

\author{
Mohammed Abu El-Hamd ${ }^{1, *}$ and Soha Aboeldahab ${ }^{1}$ \\ ${ }^{1}$ Faculty of Medicine, Sohag University, Sohag, Egypt \\ "Corresponding author: Faculty of Medicine, Sohag University, Sohag, Egypt. Email: mohammedadva@yahoo.com \\ Received 2022 January 15; Revised 2022 January 18; Accepted 2022 January 19.
}

\begin{abstract}
Trichodynia was elucidated as a distressing, painful sensation of the scalp hair and/or the skin of the scalp that becomes more vigorous when hairs are touched without an underlying cutaneous disease and is frequently associated with hair shedding. It was often more in women than men, directly correlating with hair loss. The etiology of trichodynia is not well-known, but it may be multifactorial. Several possible hypotheses can explain the etiopathogenesis of trichodynia, including enhanced expression of neuropeptide substance $P$ with perifollicular inflammation, psychiatric diseases, and nutritional deficiencies. Currently, there is no specific and effective therapy for trichodynia. Various available treatments included L-cystine-containing oral preparation, topical corticosteroid, low-dose antidepressant, oral propranolol, and botulinum toxin injection. This review article highlights an update of the definition, etiopathogenesis, diagnosis, and treatment of trichodynia.
\end{abstract}

Keywords: Hair Pain, Neuropeptide Substance P, Trichodynia

\section{Context}

Trichodynia was elucidated as a distressing, painful sensation of the scalp hair and/or the skin of the scalp that becomes more vigorous when hairs are touched without an underlying cutaneous disease and is frequently associated with hair shedding $(1,2)$. The term "trichodynia" has also been suggested for discomfort, pain, or paresthesia (burning, or stinging) of the scalp related to diffuse hair shedding $(1,3)$. Trichodynia can be distinguished from scalp dysesthesia or cutaneous dysesthesia syndrome, which denotes painful sensation, just localized on the skin of the scalp. In contrast, trichodynia denotes pain or burning sensation, affecting the scalp hair and/or the skin of the scalp (4).

\section{Prevalence}

Trichodynia was often more in women (20\%) than men (9\%) (5), with a direct correlation with hair loss (6). It has been reported that trichodynia was present in 33\% of patients with hair loss (7), while another study recorded trichodynia in $29 \%$ of patients with hair loss (3). Trichodynia was significantly prevalent in patients with telogen effluvium or telogen effluvium associated with androgenetic alopecia $(7,8)$.

\section{Etiopathogenesis}

The etiology of trichodynia is not known, but it may be multifactorial. Several possible hypotheses can explain the etiopathogenesis of trichodynia, including enhanced expression of neuropeptide substance P (SP) with perifollicular inflammation, psychiatric diseases, and nutritional deficiencies (1-8).

The SP is released from the nerve endings. It is believed that pain by the nerve endings and the alternations in the synthesis and activity of SP around the hair follicles may lead to pain and burning sensations (9). Hair follicles are innervated by unmyelinated nerve plexuses situated around the hair follicle stem cells. These nerve fibers have neuropeptides as SP and calcitonin gene-related peptide (CGRP) $(10,11)$. These neuropeptides have an essential role in the regulation of hair growth. They are implicated in neurogenic inflammation, which leads to the release of neuronal mediators involved in neuropathic pain, as may occur in the scalp associated with hair shedding (12). The SP has an essential role in hair cycle modification, mediated by stress that looks to affect the relation of this peptide with mast cells via neurokinin-1 receptors (13). It has been suggested that the painful sensation associated with trichodynia is related to the increased or dysregulated levels of SP. The underlying cause may be poor sleep because 
it is a source of stress, which can influence the regulation of SP (14).

It has been reported that $76 \%$ of the patients with trichodynia have psychopathological disorders (Anxiety, depression, or obsessive-compulsive disorders) (3, 4, 8). Anxiety and depression were possible etiological factors of trichodynia, and some researchers considered them the equivalent of vulvodynia and glossodynia $(4,8)$. In this regard, Kivanc-Altunay et al. reported associations between trichodynia and depression in patients with telogen effluvium and obsessive-compulsive disorders in patients with androgenic alopecia (3). However, Ozturk et al. reported no associations between trichodynia and anxiety or depression (15). Nutritional factors directly affect the hair (16). Neuropathic pain may result from several nutritional deficiencies (serum ferritin, vitamin B12, folate, zinc, vitamin $\mathrm{E}$, vitamin D); however, the evidence of the nutritional hypothesis, as an etiological cause for trichodynia, is very low $(8,15)$.

Recently, most of the patients with COVID-19 had telogen effluvium (66.3\%) and trichodynia (58.4\%) that started within the first four weeks after COVID-19 diagnosis, possibly because most patients with COVID-19 were under marked psychological and physiological stress. During COVID-19 pandemic, most people had great anxiety resulting from the apprehensions of the disease, fears from the outcomes of this pandemic, loss of family, and personal uncertainties about the future, which had a considerable effect on sleep. Combining enhanced stress, repeated hair wash to prevent virus transmission, and sleep disorders can lead to trichodynia and more or less being linked with hair shedding (17).

\section{Diagnosis}

The diagnosis of trichodynia relies on clinical evaluation. A detailed medical history and clinical examination are required to determine any causative factor and exclude any primary cutaneous disease (5).

\subsection{Clinical Picture}

Trichodynia was more prevalent in women than men. Women are more possibly prone to trichodynia. Women had longer hair than men, and the higher weight of the hair shaft is possibly painful. Also, anxiety has a pivotal role in the pathogenesis of trichodynia, and the female prevalence could be associated with gender-related differences in pain perception with anxiety (5). The symptoms of trichodynia were diffuse or spotty tenderness, tingling, crawling, itching, burning, and uncomfortable awareness of the scalp (6). It has been hypothesized that there was a direct association between trichodynia and hair shedding (7).

The quality and strength of the symptoms are considerably variable. The strength of the symptoms positively correlates with the severity of hair loss (18). Trichodynia can be diffused all over the scalp or localized to the painful sites of the scalp. Painful sites were discriminated by reduced thresholds of light touch and pressure pain, and increased rates of static allodynia $(6,18)$.

\subsection{Investigations}

Trichoscopy and videodermoscopy are non-invasive techniques utilizing good magnification $(20 \times-70 \times)$ and could be useful for evaluation of the scalp epidermis, follicles, hair shafts, and vascular patterns (19). Willimann and Trueb reported that only a minority of patients with trichodynia showed telangiectasia of the scalp (5). It may be explained by the uncovered expression of SP in the scalp of patients with trichodynia, which is involved in neurogenic inflammation and exerts a potent vasodilator effect (9). Assessments of serum ferritin, vitamin B12, folate, zinc, vitamin E, vitamin D, and thyroid profile could be essential in the evaluation of trichodynia $(8,15)$.

\section{Treatment}

Currently, there is no specific and effective therapy for trichodynia. There are several available treatments but with weak clinical support. Based on the inflammatory hypothesis, L-cystine-containing oral preparation and high or low potent topical corticosteroids have been recommended $(13,20,21)$. Cannabinoids can be used to inhibit SP. The capsaicin cream could be effectively used as it inhibits SP when is applied to the affected area (13). Based on the psychiatric hypothesis, low-dose antidepressants (doxepin, amitriptyline, and venlafaxine) and pregabalin can be effective in treating trichodynia $(4,22)$. Based on the neuropathic pain resulting from nutritional deficiencies (serum ferritin, zinc, vitamin B12, folate, vitamin E, vitamin D), these nutritional elements can influence the hair directly, thus dietary supplementation with these nutritional factors can influence hair growth and control pain $(8,15,16)$.

Oral propranolol (a non-selective beta-adrenergic blocking agent) can effectively treat certain patients with trichodynia (23). However, Sonthalia et al. reported a possibility of worsening depression with propranolol in patients with trichodynia (24). Botulinum toxin injection was an effective therapy in improving pain control and hair regrowth of cephalalgia alopecia patients (11). Patients with trichodynia exhibited more sensitivity to 
light touch and pressure pain and had cranial mechanical hyperesthesia and cranial hyperalgesia (18). Therefore, gentle scalp maintenance can give some relief to the pain. To encourage this therapy, it is essential to advise the patient not to utilize hot water and harsh shampoo or wear a tight ponytail. The relaxation technique, as gentle massage of the scalp, can also decrease symptoms.

\section{Conclusions}

Trichodynia is a common medical disorder. The etiology of trichodynia is not well-known, but it can be multifactorial. Numerous possible hypotheses can explain the pathogenesis of trichodynia, including enhanced expression of neuropeptide SP with perifollicular inflammation, psychiatric diseases, and nutritional deficiencies. Currently, there is no specific and effective treatment for trichodynia. Several available treatments include L-cystinecontaining oral preparation, topical corticosteroid, lowdose antidepressant, oral propranolol, and botulinum toxin injection. In this review article, we highlight an update of the definition, etiopathogenesis, diagnosis, and treatment of trichodynia.

\section{Footnotes}

Authors' Contribution: Study concept and design: M, A., and S.A.; Analysis and interpretation of data: M, A., and S.A.; Drafting of the manuscript: $\mathrm{M}, \mathrm{A}$., and S. A.; Critical revision of the manuscript for important intellectual content: F. M, A; Paper submission: M, A. All authors read and approved the final manuscript.

Conflict of Interests: None.

Funding/Support: None.

\section{References}

1. Rebora A, Semino MT, Guarrera M. Trichodynia. Dermatology. 1996;192(3):292-3. doi: 10.1159/000246391.

2. Grimalt R, Ferrando J, Grimalt F. Trichodynia. Dermatology (Basel, Switzerland).1998;196(3):374.

3. Kivanc-Altunay I, Savas C, Gokdemir G, Koslu A, Ayaydin EB. The presence of trichodynia in patients with telogen effluvium and androgenetic alopecia. Int J Dermatol. 2003;42(9):691-3. doi: 10.1046/j.13654362.2003.01847.x. [PubMed: 12956679].

4. Hoss D, Segal S. Scalp dysesthesia. Arch Dermatol. 1998;134(3):327-30. doi: 10.1001/archderm.134.3.327. [PubMed: 9521031].

5. Willimann B, Trueb RM. Hair pain (trichodynia): frequency and relationship to hair loss and patient gender. Dermatology. 2002;205(4):374-7. doi: 10.1159/000066437. [PubMed: 12444334].

6. Sulzberger MB, Witten VH, Kopf AW. Diffuse alopecia in women. Its unexplained apparent increase in incidence. Arch Dermatol. 1960;81:556-60. doi: 10.1001/archderm.1960.03730040060011. [PubMed: 13835674].
7. Baldari M, Montinari M, Guarrera M, Rebora A. Trichodynia is a distinguishing symptom of telogen effluvium. J Eur Acad Dermatol Venereol. 2009;23(6):733-4. doi: 10.1111/j.1468-3083.2009.03201.x. [PubMed: 19281607].

8. Durusoy C, Ozenli Y, Adiguzel A, Budakoglu IY, Tugal O, Arikan S, et al. The role of psychological factors and serum zinc, folate and vitamin B12 levels in the aetiology of trichodynia: a case-control study. Clin Exp Dermatol. 2009;34(7):789-92. doi: 10.1111/j.1365-2230.2008.03165.x. [PubMed: 19508569].

9. Ericson M, Gabrielson A, Worel S, Lee WS, Hordinsky MK. Substance $\mathrm{P}(\mathrm{SP})$ in innervated and non-innervated blood vessels in the skin of patients with symptomatic scalp. Exp Dermatol. 1999;8(4):344-5.

10. Paus R, Heinzelmann T, Schultz KD, Furkert J, Fechner K, Czarnetzki BM. Hair growth induction by substance. Lab Invest. 1994;71:134-40.

11. Cutrer FM, Sandroni P, Wendelschafer-Crabb G. Botulinum toxin treatment of cephalalgia alopecia increases substance $\mathrm{P}$ and calcitonin gene-related peptide-containing cutaneous nerves in scalp. Cephalalgia. 2010;30(8):1000-6. doi: 10.1111/j.1468-2982.2009.01987.x. [PubMed: 19732078].

12. Mashaghi A, Marmalidou A, Tehrani M, Grace PM, Pothoulakis C, Dana R. Neuropeptide substance $\mathrm{P}$ and the immune response. Cell $\mathrm{Mol}$ Life Sci. 2016;73(22):4249-64. doi: 10.1007/s00018-016-2293-z. [PubMed: 27314883]. [PubMed Central: PMC5056132].

13. O'Connor TM, O'Connell J, O'Brien DI, Goode T, Bredin CP, Shanahan $\mathrm{F}$. The role of substance $\mathrm{P}$ in inflammatory disease. J Cell Physiol. 2004;201(2):167-80. doi:10.1002/jcp.20061. [PubMed:15334652].

14. Xerfan EMS, Andersen ML, Facina AS, Tufik S, Tomimori J. The role of sleep in telogen effluvium and trichodynia: A commentary in the context of the current pandemic. J Cosmet Dermatol. 2021;20(4):1088-90. doi: 10.1111/jocd.13929. [PubMed: 33387387].

15. Ozturk P, Orhan FO, Ozer A, Akman Y, Kurutas E. Evaluation of Anxiety and Levels of Serum B12, Folate, TSH, Ferritin, and Zinc in Telogen Alopecia Patients with Trichodynia. Int J Trichology. 2012;4(4):2514. doi: 10.4103/0974-7753.111208. [PubMed: 23766608]. [PubMed Central: PMC3681105].

16. Rushton DH. Nutritional factors and hair loss. Clin Exp Dermatol. 2002;27(5):396-404. doi: 10.1046/j.1365-2230.2002.01076.x. [PubMed: 12190640].

17. Starace M, Iorizzo M, Sechi A, Alessandrini AM, Carpanese M, Bruni F, et al. Trichodynia and telogen effluvium in COVID-19 patients: Results of an international expert opinion survey on diagnosis and management. JAAD Int. 2021;5:11-8. doi: 10.1016/j.jdin.2021.07.006. [PubMed: 34368790]. [PubMed Central: PMC8328568].

18. Defrin R, Lurie R. Indications for peripheral and central sensitization in patients with chronic scalp pain (trichodynia). Clin J Pain. 2013;29(5):417-24. doi: 10.1097|AJP.0b013e31825e4437. [PubMed: 23246999].

19. Rakowska A. Trichoscopy (hair and scalp videodermoscopy) in the healthy female. Method standardization and norms for measurable parameters. J Dermatol Case Rep. 2009;3(1):14-9. doi: 10.3315/jdcr.2008.1021. [PubMed: 21886722]. [PubMed Central: PMC3157785].

20. Trueb RM. [Trichodynia]. Hautarzt. 1997;48(12):877-80. German. doi: 10.1007/s001050050678. [PubMed: 9486357].

21. Rebora A. Trichodynia: a review of the literature. Int J Dermatol. 2016;55(4):382-4. doi: 10.1111/ijd.13204. [PubMed: 26696219].

22. Sarifakioglu E, Onur O. Women with scalp dysesthesia treated with pregabalin. Int J Dermatol. 2013;52(11):1417-8. doi: 10.1111/j.13654632.2011.05158.x. [PubMed: 23557491].

23. Brzezinski P, Zawar V, Chiriac A. Trichodynia Silenced Effectively with Propranolol. Int J Trichology. 2019;11(1):41-2. doi: 10.4103/ijt.ijt_8_19. [PubMed: 30820134]. [PubMed Central: PMC6385513].

24. Sonthalia S, Sharma P, Agrawal M, Kapoor J. Trichodynia - A Condition Worth Treatment-Directed Evaluation Rather Than "Silencing". Int J Trichology. 2019;11(4):180-1. doi: 10.4103/ijt.ijt_71_19. [PubMed: 31523113]. [PubMed Central: PMC6706989]. 